\title{
Para uma genealogia do debate em torno da viabilidade do Estado em Timor-Leste
}

Tracing the Genealogy of the Debate on State Viability in Timor-Leste

Pour une généalogie du débat à propos de la viabilité de l'État au Timor-Leste

\section{Nuno Canas Mendes}

\section{CpenEdition}

\section{Journals}

Edição electrónica

URL: http://journals.openedition.org/rccs/5694

DOI: $10.4000 /$ rccs.5694

ISSN: 2182-7435

Editora

Centro de Estudos Sociais da Universidade de Coimbra

Edição impressa

Data de publição: 1 Setembro 2014

Paginação: 67-82

ISSN: 0254-1106

\section{Refêrencia eletrónica}

Nuno Canas Mendes, « Para uma genealogia do debate em torno da viabilidade do Estado em Timor-Leste », Revista Crítica de Ciências Sociais [Online], 104 | 2014, colocado online no dia 23 setembro 2014, criado a 19 abril 2019. URL : http://journals.openedition.org/rccs/5694; DOI : $10.4000 /$ rccs. 5694 


\title{
NUNO CANAS MENDES
}

\section{Para uma genealogia do debate em torno da viabi- lidade do Estado em Timor-Leste}

\begin{abstract}
O artigo procura traçar uma genealogia do debate em torno da construção e da viabilidade do Estado em Timor-Leste, desde os alvores da ideia de independência aos nossos dias: percorre o período 1974-75, a ocupação indonésia até ao início e termo da administração internacional das Nações Unidas (1999-2002) e finalmente a assunção da soberania em 2002, com os subsequentes desafios e dificuldades desde então sentidos. Este debate reflete tensões políticas de âmbito regional e internacional e deve ser inserido nos contextos históricos específicos em que ocorreu tal produção discursiva. Para além da definição de um quadro conceptual que se ensaia na aplicação ao caso, serão analisadas as posições dos principais intervenientes externos no processo, Estados e organizações internacionais, cujas motivações serão objeto de reflexão.
\end{abstract}

Palavras-chave: formação do Estado; Estados falhados; pós-guerra; processo de paz; Timor-Leste.

O propósito deste artigo é analisar, numa perspetiva histórica, algumas das práticas discursivas, académicas e políticas, em torno do misterioso e vago, por vezes polémico, quando não vácuo, conceito de viabilidade do Estado, no âmbito mais alargado dos temas da construção do Estado e da construção da nação em Timor-Leste. Dos primeiros ensaios, ainda nos anos 1970, sobre a ideia de nação e da sustentabilidade da mesma, passando pelo longo período da Resistência, assumindo particular destaque a administração das Nações Unidas, o seu legado e as missões sucessórias, até à significativamente denominada 'restauração' da independência, o tema suscitou uma ampla discussão que carece de análise cuidada e que não cabe num artigo de pequena dimensão como o presente. Há em todo o caso, um encadeamento 'genealógico' que se pode ensaiar.

É importante referir, à partida, que o artigo tem vários objetivos, que devem ser, no entanto, sempre considerados na ótica do levantamento de pistas: desde logo, identificar e caracterizar o discurso em torno da construção do Estado e da nação e os respetivos desafios e problemas. Tal ocorre 
basicamente nos marcos temporais que a seguir se avançam: 1) no período 1974-75: as primeiras tomadas de posição, dos académicos aos políticos; 2) no período 1999-2002: com o horizonte da soberania e a criação da administração das Nações Unidas, toma forma o discurso sobre 'State-Building' e 'Nation-Building';3) de 2002 aos nossos dias: independência/restauração, disrupções políticas e seus efeitos para a continuação do debate e a ideia da 'neotutela' associada às missões sucessórias das Nações Unidas.

A complexidade, originária e constante, da questão de Timor-Leste chamou sempre a atenção para a centralidade da fundação no Estado, na medida em que esse objetivo imbricava com o princípio da autodeterminação, com o pós-colonialismo e com o papel das organizações internacionais, das organizações não governamentais e dos indivíduos, cuja ação, mais ou menos conjugada, redundou, com a ajuda conjuntural e a mudança de cenário estratégico nas relações internacionais, na alteração ao status quo e na reunião das condições que, permitindo a independência formal, a envolveram numa nebulosa de desafios e numa fixação vaga de conceitos tornados em objetivos políticos.

Como em tantos outros casos, um processo que é um 'microcosmos' da história das relações internacionais do último quartel do século xx e do primeiro do século XXI, neste particular com as especificidades que resultam de três administrações sucessivas 'estrangeiras' (portuguesa, indonésia e da ONU) e de uma última que sendo 'nacional', esteve entre 2002 e 2012 acompanhada de duas missões sucessórias das Nações Unidas (United Nations Mission of Support in East Timor, UNMISET, 2002-2005 e United Nations Mission in Timor-Leste, UNMIT, 2005-2012), cujo fim era justamente auxiliar o Estado nas tarefas tradicionalmente resultantes do exercício da soberania.

\section{A genealogia}

Avancem-se os primeiros passos para traçar esta genealogia. O debate tem de ser visto à luz da Teoria das Relações Internacionais, através da qual numa visão puramente simplista, a polarização que se instalou entre idealistas e realistas, uns apologistas os outros detratores, ganhou nova densidade de cor no imediato pós-Guerra Fria, com as várias intervenções, ora por parte da sociedade internacional, em ações legitimadas pelas Nações Unidas em situações de crise ou de conflito, ora, em alternativa, por parte de um Estado ou de uma coligação de Estados, nem sempre detentores dessa mesma legitimidade. A questão é, naturalmente, muito mais matizada e tem dado azo a uma outra discussão em torno da intervenção externa, das condições que fundamentam a ingerência, e da fonte de legitimidade que um mandato 
das Nações Unidas confere para que essa intervenção ocorra. No processo de fabricação de um país a parafernália de atores envolvidos leva a cabo ações efetivas para erigir as instituições, mas são frequentes as acusações de neocolonialismo ou de pré-formatação e desatenção às especificidades dos territórios em que se movem. Nesta dinâmica mecanicista de sabor artificial, é frequente identificarem-se situações de extrema delicadeza, verdadeiramente não tipificadas, mas que envolvem cenários de instabilidade, disfunções institucionais ou pobreza: neste caso, a construção do Estado pode redundar numa situação de 'fragilidade', expressão que alguns estudiosos preferem, evitando assim outra mais definitiva como 'falhanço' (tradução não completamente satisfatória para failure) ou 'colapso'.

É verdade que nunca houve um otimismo muito acentuado em relação à criação de Timor-Leste. Desde o início do projeto de Estado-nação e mesmo antes (quando Sukarno demonstrou a sua vontade de integrar o território na Indonésia, nos anos 1960), que estão identificados vários escritos que enumeram as dificuldades do estatuto. Muitos analistas, incluindo militares, especialistas em informações e até mesmo académicos mostraram ser reticentes em relação à viabilidade de um Estado na metade oriental da ilha de Timor. Nos meados do decénio de 1970, depois de Portugal ter pronunciado a sua vontade de descolonizar, a perceção geopolítica e a avaliação das condições económicas apontavam para a impossibilidade da independência; a Indonésia, apoiada pelos EUA, pretendia a anexação e a Austrália apoiava-a nessa pretensão; Portugal, embora reconhecesse o direito à autodeterminação, tinha a consciência de que a elite local estaria insuficientemente preparada para levar por diante um novo país e que a violência iria irromper de imediato.

Depois de 1975 e até 1999, a luta pelo reconhecimento da legitimidade da intenção de fundar um Estado-nação tomou menos em conta a sustentabilidade da soberania, o que de resto nem sequer é incomum. As Nações Unidas levaram a cabo várias missões de construção de Estados, com complexidades e amplitudes crescentes nos últimos vinte anos e sujeitas a exigente escrutínio, no afã, aparentemente impossível, de assinalar o respetivo êxito. De 2002 em diante, o novo Estado assumiu a responsabilidade, ainda que parcialmente partilhada, com as missões sucessórias das Nações Unidas e com a ajuda internacional e bilateral, de certos parceiros privilegiados. Veio para discussão a ideia de neotutela, rebuscada na história, assunto tratado mais adiante.

\section{Alguns conceitos-chave}

Em seguida, apresentam-se brevemente os conceitos-chave para o debate, após o que será ensaiada a aplicação dos mesmos a Timor-Leste, identificando 
as linhas de continuidade assim como as de rutura, de 1975 aos nossos dias. Não pretendendo entrar numa deambulação sobre conceitos, é importante fixá-los no enquadramento histórico devido, bem como na tendência para a concentração na análise dos resultados e nas dificuldades, quando não impotência, da comunidade internacional. O que o fim do bipolarismo e a reemergência dos nacionalismos trouxe foi a produção de um novo conceito-categoria de Estado indutor de um estigma: o Estado falhado. Esta classificação foi revista, poucos anos mais tarde, como puramente instrumental, na medida em que a conjuntura da War on Terror e a aplicação da política externa americana na repressão dos Rogue e dos Failed States constituíam uma base, unilateral, para a intervenção externa. ${ }^{1}$

À luz das teorias das Relações Internacionais era, como se referiu, fácil de estabelecer a dicotomia entre os realistas, que viam nestas novas entidades terreno fértil para políticos corruptos e um viveiro para terroristas, uma ficção insustentável a requerer assistência internacional permanente e uma verdadeira ameaça à segurança internacional. Os liberais, por seu turno, acreditam que a organização de um sistema democrático era não só desejável e expectável, como possível, e que a construção de um Estado dotado de instituições funcionais e o desenvolvimento da economia, devidamente integrada nas forças e dinâmicas da globalização, são um benigno ponto de partida.

A citada formulação - o Estado falhado -, originalmente concebida nos Estados Unidos, foi usada para rotular todos os Estados onde ocorreram guerras mortíferas (com um elevado número de vítimas civis), deslocações de populações, pobreza, má-nutrição e ausência de segurança, cuidados de saúde e educação (Rotberg, 2002: 127). ${ }^{2}$ Robert Jackson descreveu estes Estados como detentores do que chama soberania negativa na medida em que, sendo reconhecidos pelos seus pares, não têm os recursos suficientes e

\footnotetext{
${ }^{1}$ O termo 'Estado falhado' ganhou destaque com a publicação do artigo de Gerald B. Helman e Steven R. Ratner, "Saving Failed States", Foreign Policy, 89(3) (inverno, 1992-93). Nele é descrito enquanto "absolutamente incapaz de se manter a si próprio como membro da comunidade internacional"). A conceção, muito ampla e suscetível de equívocos, deixou uma marca terminológica importante.

2 Rotberg descreve um cenário 'familiar' no plano mundial e portanto pouco operacional: "Um Estado falhado é uma entidade política vazia que já não tem vontade ou capacidade de desempenhar as principais tarefas de um Estado-nação no mundo moderno. As suas instituições são disfuncionais. Se porventura existir poder legislativo, ele só ratifica as decisões de um executivo forte. O debate democrático está ausente. O poder judicial deriva do executivo em vez de ser independente. Os cidadãos sabem que não podem confiar nos tribunais para reparações ou indemnizações, sobretudo contra o Estado. A burocracia do Estado há muito que perdeu o seu sentido de responsabilidade profissional e ajuda a oprimir os cidadãos". Jackson, mais conciso, apresenta uma definição de Estado falhado para designar aquele que "não pode salvaguardar ou não salvaguarda condições mínimas às suas populações: paz doméstica, ordem, direito e boa governação” (Jackson, 2000).
} 
a vontade para satisfazer as necessidades do respetivo povo (Jackson, 1993). Como se vê, a questão encerra uma tensão ideológica, mas o ponto essencial é apreender o alcance analítico do conceito: saber em que consiste, através de que critérios é estabelecido e por quem. A realidade sociológica existe e perturba a segurança internacional; a tendência para uma certa perceção organicista, quando não mesmo antropomórfica, é inevitável, mas estes são outros debates, que não cabem neste texto. Têm sido cunhadas expressões similares, como 'Estados em colapso' ou 'Estados frágeis', as quais surgem como alternativas para descrever situações de 'morte' e outras moderadamente menos graves. Tal parece não resolver o problema da aplicação dos conceitos à realidade, nem mesmo com a criação de índices definidos por instituições privadas e revisões periódicas de classificações (Rotberg, 2004). ${ }^{3}$ O fim da Guerra Fria trouxe para a ribalta diversas crises (Somália, Ruanda, ex-Jugoslávia) que sublinhavam os efeitos do fenómeno na segurança internacional. A ONU, em consonância com esta tendência, alargou a sua já pesada agenda, constituindo missões de paz e produzindo quantidades massivas de wishful thinking, cunhando ou modulando expressões como good governance, transparency ou capacity building. A União Europeia, por seu turno, incorporou o tema na sua Política de Segurança e Defesa com a inclusão do 'State failure' no seu Conceito Estratégico de 2003.

O discurso do Estado falhado segue a tradição da escola da modernização que assume que a evolução natural é o caminho do Estado liberal. Portanto, quando um Estado falha é porque não atingiu o modelo do Estado lockiano, com a provisão de serviços (segurança, rule of law, participação política, saúde e educação), ou weberiano, com o monopólio da violência (Eriksen, 2010). É evidente a referência norte-americana, nessa mescla de wilsonianismo e realpolitik, a qual induziu uma tradição intelectual que se generalizou como modelo de governança internacional. Mas, mesmo assim, e apesar dos esforços empreendidos, continua a não haver consenso quanto às características definidoras do conceito. A procura da fórmula confronta-se com dados empíricos de difícil tipificação. Um caso de desconstrução

\footnotetext{
3 Rotberg propôs uma definição para Estados fracos: "Estados fracos incluem um conjunto de Estados-nação que podem ser inerentemente fracos por constrangimentos geográficos, físicos ou fundamentalmente económicos; ou podem ser ocasionalmente fracos devido a antagonismos domésticos, cobiça ou despotismo. Os Estados fracos dão habitualmente abrigo a tensões étnicas, religiosas, linguísticas ou outras, que podem até certo ponto transformar-se num conflito entre fações. [...] As infraestruturas físicas estão deterioradas. As escolas e os hospitais dão sinais de negligência. O PIB per capita e indicadores similares caíram ou encontram-se em queda, por vezes dramaticamente. Os níveis de corrupção são altos e tendem a aumentar. O Estado de direito é uma ficção. A sociedade civil encontra-se anémica. Os déspotas mandam. [...] Os Estados em colapso são raros e versões extremas de um Estado falhado".
} 
pós-modernista a funcionar em pleno: o esvaziamento do sentido e a instrumentalização como traços principais da sua aplicação à realidade.

\section{O debate sobre o 'Estado falhado' em Timor-Leste}

Christopher Hill, à época Secretário de Estado Adjunto norte-americano para Assuntos da Ásia Oriental e Pacífico, visitou Timor-Leste em Abril de 2008 e declarou prontamente que este não era um Estado falhado. Fora de contexto, a declaração sugere uma boutade: se os Estados Unidos, pela voz do seu governo, não rotularem Timor-Leste nessa categoria, então Timor-Leste não é, na verdade, um Estado falhado. Este silogismo está de facto ligado a um contexto muito particular já aqui mencionado. Mas o que é realmente o principal objetivo deste texto é destacar a genealogia do conceito aplicado a este projeto de Estado em Timor-Leste.

No que se refere a este país, o horizonte da autodeterminação, definido em 1974, provocou imediatamente uma reação dos dois países vizinhos, Indonésia e Austrália, dos Estados Unidos e de Portugal. Segundo todos eles, Timor não estaria preparado para sobreviver economicamente, as elites conflituantes ensombravam qualquer futuro promissor e seria, antecipavam, altamente provável que o território viesse a ser submetido a desestabilizadoras 'infiltrações'.

Esta perceção de incapacidade não era inteiramente nova: nos anos sessenta, como Moisés Silva Fernandes revelou, o futuro de Timor-Leste tinha sido traçado pelas quatro potências mais diretamente envolvidas na área: EUA, Indonésia, Austrália e Reino Unido. Portugal não teve qualquer participação nas negociações. Na mesma década, a ideia de integrar o então Timor Português na Indonésia começou a ser anunciada no final da época de Sukarno (agosto de 1965), na sequência de um movimento nacionalista de influência islamo-malaia (Fernandes, 2005; 2006).

Entre 1974 e 1975, o Governo da Indonésia seguiu atentamente a evolução política e confirmou a ideia da reunião quadripartida mencionada acima: a absorção parecia inevitável. Hoadley anteviu uma intervenção rápida, na medida em que a situação em Timor-Leste poderia ser uma ameaça à integridade da Indonésia, ameaça esta que decorria do medo de que a diminuta dimensão de Timor, bem como o atraso económico e vulnerabilidades várias, o tornassem num potencial espaço vazio de poder, atraindo poderes externos hostis, quer diretamente, através do comércio, ajuda, e bases militares, quer clandestinamente, através de agentes radicais ou comunistas, com tropas hostis, perto da fronteira da Indonésia, oferecendo um canal de infiltração e apoio aos grupos de oposição dentro da própria Indonésia" (Hoadley, 1975). A Indonésia temia que a União Soviética ou a China, especialmente 
esta última, pudessem apoiar a Frente Revolucionária para um Timor-Leste Independente (FRETILIN).

Estes receios foram naturalmente exagerados pela propaganda, técnica em que os indonésios foram muito bem-sucedidos. O jornal Berita Yudha, de 2 de dezembro de 1974, denunciava os excessos intimidatórios da FRETILIN. Os seus apoiantes andariam igualmente a mostrar uma foto de Mao Tsé-Tung aos adeptos da Associação Popular Democrática de Timor (APODETI), como grande mentor, exortando-os a rejeitar a integração. A contrainformação foi alimentando a instabilidade e a imprensa em Jacarta começou a informar que a APODETI era apoiada por um número crescente de timorenses que desejavam tornar-se indonésios (Hoadley, 1975: 17). O ministro dos Negócios Estrangeiros, Adam Malik, no final de 1974, anunciava que a anexação parecia ser a única solução (apud Hoadley, 1975: 9). Tudo não passava de uma questão de tempo.

Acresce que o processo de descolonização em curso também originava variadíssimas dúvidas. Vozes críticas, como Ruy Cinatti, viam com acentuado pessimismo a independência de Timor-Leste:

não posso conceber uma independência digna desse nome que não assente num mínimo de condições materiais [...] e de estruturação administrativa que a assegurem. [...] sem recursos técnicos e financeiros vindos do exterior e sem que o homem se transforme mergulhando na realidade local antes mesmo que as ideologias preferenciais a possam activar, será pouco menos que impossível a manutenção de uma independência à escala do que, como tal, é hoje consenso universal. (apud Stilwell, 1995: 8 ss.)

No Parlamento português, em janeiro de 1976, um mês após a invasão indonésia, num discurso, o deputado Ângelo Correia, declarava o seguinte:

Timor apresenta-se como um dos territórios mais atrasados de todo o mundo, sem infra-estruturas físicas e produtivas, sem quadros técnicos e, sobretudo, sem uma elite minimamente capaz de assegurar completamente a gestão do território. A sua manutenção como nação independente obrigaria ou a um permanente auxílio de instâncias internacionais, com profundas implicações na capacidade decisória interna dos seus povos, ou a uma utilização do seu território por potências externas que, aproveitando-se da sua localização, poderiam ser tentadas a alterar o equilíbrio estratégico na área [...]. Em síntese, parece-nos existirem fortes possibilidades de a independência imediata poder conduzir ou a um neocolonialismo económico-militar, ou à extinção da nação, ou, por último, à manutenção de uma situação de permanente subdesenvolvimento letárgico. (Assembleia da República, 2000: 65) 
Assim, o fantasma do fracasso está associado, desde o início, à ideia de fundação do Estado e, apesar do facto de a conjuntura internacional se ter alterado profundamente, durante o período de transição (1999-2002) este debate teve seguimento. A reflexão sobre o modelo de administração das Nações Unidas, em especial o papel e as tarefas de "construção da nação" e "construção do Estado", sublinhou a importância de preocupações inteiramente novas: o relançamento da economia, do Estado de direito, da confiança no desenvolvimento da sociedade civil, incluindo uma infinidade de questões como a estabilidade fiscal e macroeconómica, os salários dos funcionários públicos, emprego, tribunais com um funcionamento eficiente, construção de estradas e reparação de redes de telecomunicações, etc. Este desafio implicaria um grande investimento em recursos humanos e, principalmente, a continuidade da ajuda internacional - a qual não poderia ser tomada como garantida para sempre. A Organização das Nações Unidas, que nunca tinha tido um mandato de tamanha amplitude para administrar um território, com a trindade dos poderes, começou por ser apresentada como tendo empreendido uma missão coroada de êxito. Não por muito tempo, é justo acrescentar. Durante a vigência da United Nations Transitory Administration for East Timor (UNTAET), um significativo número de críticos oscilaram entre dois argumentos. Alguns deles sustentavam a incapacidade das Nações Unidas - por causa da sua estrutura e agenda -, no cumprimento das metas a que se havia comprometido, assim como a incapacidade de adaptação ao terreno e de encontrar respostas adequadas. Os outros consideravam que o fim da UNTAET havia sido prematuro. Jarat Chopra foi talvez o mais proeminente dos críticos da atuação das Nações Unidas em Timor-Leste, num artigo intitulado "Building State failure in Timor-Leste" (2002), onde pinta um cenário muito sombrio, prevendo um fracasso do Estado em Timor-Leste devido às práticas inadequadas da organização: a forma 'absolutista' de exercer a autoridade e a falta de 'intervenção participativa', que a timorização, ou seja a integração de alguns timorenses na administração, só parcialmente resolvera (Chopra, 2002).

Robert Rotberg foi menos destrutivo, considerando que Timor-Leste dependeria das injeções de capitais da comunidade internacional. No entanto, detetou vários sintomas potenciais de 'fracasso', evocando a suficiente vontade política e a assistência externa dirigida. Embora isto seja do senso comum, mas subsume a herança do liberalismo, de ascendência wilsoniana.

Os realistas tiveram voz num Howard J. Wiarda, um antigo conselheiro do presidente Bush pai. Em 2002, defendeu que em Timor-Leste se reuniam 
todas as condições para haver 'fracasso', descrevendo a situação com cores previsivelmente muito sombrias:

É um dos países mais pobres do mundo. Não só é subdesenvolvido económica e socialmente em praticamente todos os aspetos, como quase não tem instituições com as quais se possa contar: não tem governo, funcionalismo público, sociedade civil, tradição de governação própria, de democracia ou de cultura política cívica. Quase não tem agricultura, ou a que tem é muito fraca, não tem comércio, indústria ou comércio externo. (Wiarda, 2002: 53)

Wiarda anteviu que as forças da ONU e outros atores internacionais seriam suscetíveis de permanecer no país por muitos anos.

Durante a crise de 2006-2008, a questão foi levantada novamente. Começando com a contestação à Igreja Católica, seguida do episódio dos "Peticionários" 4 e da crise no seio das Forças Armadas, a demissão de Mari Alkatiri, as eleições presidenciais e legislativas e depois as tentativas de assassinato de Ramos-Horta e Xanana Gusmão, todo o país pareceu mergulhar em tumulto. Os adivinhos voltaram; as tensões entre idealistas e realistas surgiram novamente. Algumas vozes foram cuidadosas: ainda que permanecesse numa situação frágil, Timor-Leste não estava à beira de uma iminente implosão, nem merecia o rótulo de Estado falhado. Os contornos internos da crise corroboravam os estereótipos: instituições frágeis, problemas de segurança, tensões sociais e étnicas, pobreza. O prolongamento das missões das Nações Unidas (UNMISET, UNMIT) e a intervenção de poderes bilaterais, com a Austrália à cabeça, para garantir um ambiente de segurança, vinham confirmar a fragilidade de toda a situação.

Este período de 2006 a 2008 e o envolvimento crescente da Austrália coexistiam com uma manifestação de interesses por parte da China, cuja visibilidade

\footnotetext{
${ }^{4}$ O episódio dos 'Peticionários' foi uma crise desencadeada por cerca de 600 militares das Falintil - Forças de Defesa de Timor-Leste (F-FDTL), antigos guerrilheiros, apresentados como oriundos da parte ocidental do país, que alegando ser alvo de discriminação da instituição a que pertenciam, apresentaram uma 'petição' ao chefe de Estado e ao chefe de Estado-Maior General das Forças Armadas a 9 de janeiro de 2006, tendo abandonado os quartéis a 17 de fevereiro e recebido a exoneração a 16 de março. $O$ facto deu origem a posteriores manifestações com várias cenas de violência e vítimas mortais incluídas, tendo vindo a chamar a atenção para a existência de um problema estrutural de segurança, por impreparação das forças locais, resolvido com a intervenção externa multilateral e bilateral. A questão adquiriu contornos diversos, desde a fricção étnica entre Leste e Oeste, passando por um conflito de papéis com a Polícia Nacional de Timor-Leste (PNTL) e teve um desenvolvimento com o levantamento do Major Alfredo Reinado em apoio dos Peticionários, desafiando claramente as autoridades (maio). Seguiu-se a intervenção da Australian Defence Force (maio) e a demissão do Governo de Alkatiri (junho). Sobre o assunto, leia-se Damien Kingsbury e Michael Leach (orgs.) (2007), East Timor beyond Independence. Clayton: Monash University Press.
} 
se foi tornando cada vez maior, no estilo habitual da política externa chinesa (Mendes, 2009). A dependência securitária em relação à Austrália e a crescente penetração económica chinesa tornavam o país num local de confluência e competição de interesses.

Em 2012, a realização de eleições, presidenciais e legislativas, e o anunciado fim da presença das Nações Unidas lançou um conjunto de novas interrogações, desta vez com a tónica numa situação sem precedentes, o fim da 'tutela' multilateral. Hillary Clinton visitou o país em setembro deste ano, o que foi lido por alguns setores como uma forma de aproximação ao país geograficamente mais perto da Austrália, em cujo Norte (Darwin, mais exatamente), se basearam 2500 marines por forma a conter a expansão chinesa na região. ${ }^{5}$ Doravante, o destino do país, nas suas vulnerabilidades bem identificadas, entrará num ciclo de novas incertezas em que há retração do multilateral mas não do bilateral. Será ainda prematuro avançar para avaliações, muito embora existam sinais positivos de crescimento económico, sem embargo das assimetrias subsistentes e da dependência do fundo soberano (Mendes, 2012).

\section{A Austrália e o discurso do 'Failed State'}

Como é sabido, a Austrália, devido à sua proximidade da Indonésia e por razões de segurança, defendeu a integração de Timor na Indonésia, em 1974. Num encontro com Suharto, em 6 de setembro de 1974, o Primeiro-Ministro Gough Whitlam considerou que o território era muito pequeno para ser independente. Numa frase curta, Whitlam definiu a posição do Governo da Austrália, inaugurando o discurso sobre o tema: "Um Timor-Leste independente será um Estado inviável e uma ameaça potencial para a região" (Ishizuka, 2004). Nesta reunião, Suharto sublinhou a impossibilidade económica de um Timor-Leste independente e o previsível pedido de auxílio a países inimigos - a China ou a União Soviética. Desde então e até ao final de 1998 houve um consenso, tanto entre Liberais como Trabalhistas, sobre a prioridade de manter boas relações com a Indonésia.

Após a independência em 2002, o debate ganhou novo fôlego. O fracasso previsto, anunciado pelas aludidas vozes de Chopra e Wiarda, teve repercussões na Austrália. Vários analistas compararam o caso de Timor-Leste com situações semelhantes em ilhas do Pacífico Sul, em que a Austrália interveio. Desde 2001, o governo começou a desempenhar um papel mais assertivo na vizinhança, pois, como declarou o então Primeiro-Ministro John Howard:

\footnotetext{
5 Timothy Lynch, da University of Melbourne, comentou: "seria uma notável coincidência se ambos os factos não estivessem relacionados”, The Wall Street Journal, 05.09.2012.
} 
É do interesse da Austrália e dos nossos vizinhos das ilhas do Pacífico o esforço por uma região que seja economicamente viável, politicamente estável e sem criminalidade. Os custos financeiros e ameaças potenciais dos Estados falhados à Austrália, incluindo o crime transnacional e o terrorismo internacional, seriam imensos. (Australian Government, 2004)

Timor-Leste pertence geograficamente ao Sudeste Asiático, mas não seria estranho relacionarem-se as suas características com a área da Melanésia. As semelhanças são facilmente reconhecíveis. Em 2003, a Austrália definiu como orientação da sua política externa a "intervenção cooperativa" e tornou-a realidade nas Ilhas Salomão, Papua Nova Guiné, Tonga e Ilhas Fiji (Wainwright, 2003). Todos estes territórios, incluindo também Timor-Leste, foram integrados na sua esfera de influência, formando o que chamaram de "arco de instabilidade". O risco de fracasso, regional e estadual não se limitava, na posição do governo, ao Pacífico-Sul. E Timor-Leste possuía muitas das características do potencial de fracasso, incluindo uma economia estagnada, poucas perspetivas de emprego, as tensões em torno da reintegração de veteranos da Resistência na sociedade e instituições débeis, uma polícia disfuncional e um sistema judicial ineficiente. ${ }^{6}$

Segundo essa conceção, Timor-Leste parecia estar na linha do citado arco. Sendo um dos países mais pobres do mundo e a experimentar graves problemas, Timor-Leste seria uma potencial fonte de instabilidade. E, simultaneamente, a Austrália estenderia a sua influência política e económica através do comércio e cooperação.

A crise de 2006 foi relatada pelo ministro das Relações Exteriores, Alexander Downer, como segue: “Timor-Leste tinha potencial para se tornar num Estado falhado, se a volátil situação política e securitária não tivesse sido controlada" (News.com.au, 2006).

$\mathrm{Na}$ verdade, a Austrália enviou as suas tropas para Timor, com autorização da UNMIT, e continuou a salientar a necessidade de continuar uma ajuda sustentável, a fim de evitar a desordem. O texto da AusAid era claro sobre o Estado de Timor-Leste, usando as palavras fraco e frágil para descrever a situação (AusAid, 2008). ONG como a Oxfam, embora em alerta contra o aumento da influência australiana, também ressaltam os perigos em que Timor estava incorrendo: "Dois anos depois de alcançar a independência, Timor-Leste está em risco de se transformar num Estado falhado, com a abordagem do Governo australiano de negociação da fronteira

$\overline{6}$ Ver James Cotton (2007), "Timor-Leste and the Discourse of State failure”, Australian Journal of International Affairs, 61, 455-470. 
marítima a impedir a capacidade da nova nação de financiar o seu desenvolvimento a longo prazo" (Oxfam, 2004).

A mudança de ciclo político na Austrália, em 2007, evidentemente não alterou o que são os interesses permanentes da política externa deste país nem sequer a preocupação securitária recorrente e a assistência ao pequeno Estado, ainda que a terminologia tenha sofrido um expectável abrandamento, que de resto, independentemente do estilo dos Trabalhistas, também corresponde a uma acalmia na situação interna de Timor-Leste et pour cause.

\section{A ideia de neotutela}

Não pretendendo entrar em considerações sobre o conceito e implicações da neotutela, tema sobre o qual já muito se escreveu, a atenção recairá sobre a sua aplicação ao caso de Timor-Leste. ${ }^{7}$ A questão foi discutida como eventual formato que conciliasse as dificuldades de aplicação ao terreno de um mandato, equilibrando as dificuldades sentidas pelo Estado no exercício das suas funções. Uma solução de aplicação temporária e não necessariamente imperialista, que implica a coparticipação local e internacional num modelo que em certa medida foi timidamente ensaiado durante a UNTAET e que por solicitação das próprias autoridades timorenses não foi formalmente aplicado através das missões sucessórias, com vigor especial a partir da crise de 2006, por ter sido posta em causa de modo veemente o desempenho do Estado, designadamente na sua tarefa securitária.

Richard J. Butler, num artigo que é dedicado a esta questão, argumenta que o envolvimento da $\mathrm{ONU}$ em Timor-Leste não corresponde ao conceito de neotutela e que de uma forma mais adequada a neotutela deve ser vista como o produto da disjunção entre o mandato definido e a incapacidade organizacional de o cumprir num complexo ambiente pós-conflito, mais do que como qualquer manifestação intencional e instrumental de 'imperialismo pós-moderno' (Butler, 2012: 85 ss.). Butler avança, portanto, uma explicação benigna: a incapacidade é atribuída ao formato, isto é ao desfasamento entre a obrigação 'custodial' das Nações Unidas de manter a paz e a segurança em sociedades pós-conflito e a falta de capacidade para o alcançar e, consequentemente, não considera que haja um regresso ao imperialismo

\footnotetext{
${ }^{7}$ Sobre a neotutela, recomendam-se os seguintes artigos: James D. Fearon e David D. Laitin (2004), "Neotrusteeship and the Problem of Weak States", International Security, 28(4), 5-43; Robert Caplan (2007), "From Collapsing States to Neotrusteeship: The Limits to Solving the Problem of 'Precarious Statehood' in the $21^{\text {st }}$ Century", Third World Quarterly, 28(2), 231-244; Stephen D. Krasner (2004), "Sharing Sovereignty, New Institutions for Collapsed and Failing States", International Security, 29(2), 85-120.
} 
em que as Nações Unidas reificam institucionalmente a hegemonia liberal, sob o disfarce de State-building.

A neotutela é por definição multilateral e transitória, procurando promover melhor governação em Estados falhados, em colapso ou em sociedades pós-conflito. Ora, no caso vertente, argumenta Butler, a 'incapacidade' redundou em pouco envolvimento local (com o Conselho Nacional de Resistência Timorense, CNRT e as Falintil); na frustrada tentativa de 'timorizar' através da criação do Conselho Consultivo Nacional para servir de interface entre a UNTAET e os timorenses (dezembro de 1999), cujos membros, não eleitos, tinham uma representatividade polémica; e apenas no verão de 2000 a East Timor Transitory Administration (ETTA) e em outubro o Conselho Nacional (já todo formado por timorenses), são um sinal, ainda que pouco ousado, do ajustamento às características do terreno. Ora é justamente esta ideia que de novo põe a tónica na capacidade de autogoverno e na inoperacionalidade das Nações Unidas em atingirem, com o nível de ambição definido, os objetivos a que se propõem.

De certa forma, a ideia do desajustamento entre o mandato e a aplicação acabou por não ser ultrapassada, ainda que tenha criado uma dinâmica de interdependência entre a assistência das Nações Unidas e a construção das instituições, que lançou uma ideia de gestão por neotutela como um meio de superar a fragilidade dos Estados. O ensaio de administração internacional em Timor foi uma solução contestada porque não se encontrou na fórmula de coparticipação um equilíbrio; as missões sucessórias também não tocaram, no âmbito definido, senão ao de leve uma sugestão de neotutela, que não saiu portanto do plano da discussão teórica.

\section{Conclusões}

O choque entre liberalismo e realismo e a abordagem pós-moderna ficam bem patentes na análise da evolução do discurso em torno da construção do Estado e da Nação, e nas agruras dessas duas tarefas. O debate evoluiu desde a perspetiva colonial até ao ambiente pós-Guerra Fria, no decénio de 90 do século passado, em que a intervenção humanitária, as administrações internacionais e a alusão à ocorrência de 'Estados falhados' se tornaram frequentes. Em diferentes contextos históricos, o discurso sobre o 'Estado falhado' ou sobre a 'fragilidade de Estados' tem servido claros fins políticos e reflete forçosamente opções ideológicas, bem como diferentes interpretações das relações internacionais e visões diferenciadas sobre a natureza, funções e evolução do Estado. Na sua aparente inoperacionalidade e quase vacuidade classificatória, torna-se importante contextualizar historicamente a evolução do discurso tentando apreender de que forma as suas modulações 
são o espelho da agenda internacional e, num contexto mais particular, as agendas dos atores mais diretamente envolvidos.

O caso de Timor-Leste é, com efeito, um bom caso de estudo desta questão. Desde que o horizonte da independência se perfilou, nos anos 1970, que os vaticínios pessimistas abundaram. Por diferentes razões, a Austrália e a Indonésia justificaram as suas posições antes e após a invasão conduzida pelo segundo com a conivência e depois aprovação do primeiro em nome de um potencial colapso do projetado Estado; Portugal oscilou entre a omissão e o ceticismo de duas ou três vozes. Porém com os juízos da realpolitik alterados, o idealismo venceu, e, em 1999, a independência tornou-se um objetivo possível de alcançar. A transição não foi, como seria de esperar, isenta de deambulações em torno da questão. As Nações Unidas, na sua missão de construção do Estado, foram acusadas de terem legado um Estado frágil ou mesmo falhado e de terem prematuramente transferido a administração, mesmo que tenham continuado o seu trabalho de assistência nas missões sucessórias.

Os desenvolvimentos posteriores mostraram exaustivamente que, nos seus primeiros passos, se verificaram situações no jovem país que contribuíram amplamente para a produção do discurso. Estavam reunidas as condições para tentativas mais ou menos genuínas de promover não só a compreensão sobre a natureza e os processos que conduzem às situações concretas de debilidade ou colapso, mas também sobre os motivos de natureza política da produção do discurso. Este ponto é essencial: o que, sem dúvida, importa é examinar atentamente as razões pelas quais os principais intervenientes envolvidos em Timor-Leste estiveram interessados em produzir tal discurso, independentemente de ele poder ter sustentação numa realidade caracterizada pela instabilidade política, a insegurança ou a fruste economia. Tais razões podem ser aduzidas sem dificuldades de maior tendo por base duas premissas, a de que não se discute a 'bondade' da realidade estadual e de que esta bondade tem cânones próprios, vagamente definidos em receitas genéricas e pouco discutidas. Assim, autojustificação para a existência das instituições, defesa de interesses egoístas, crença numa qualquer paz perpétua e na inexorabilidade do progresso ou tão-somente a necessidade de criar uma realidade única, podiam ser, entre outras, condições para a atividade discursiva que sustenta a construção e a fragilidade ou colapso dos Estados. As Nações Unidas e as organizações internacionais, os Estados, as ONG e toda a sorte de atores são animadas por motivações diversas para debitarem tal discurso. Neste texto procurou-se chamar a atenção para esta tendência e respetivas motivações numa ótica genealógica.

Se esta tarefa nos faz chegar a conclusões interessantes ainda está por provar. Que a história está cheia de exemplos de Estados que desapareceram 
é uma evidência, e de outros que 'miraculosamente' têm sobrevivido também. O fatalismo, provou-se, é tudo menos linear quando se trata de traçar a história de Timor-Leste.

Artigo recebido a 23.02.2014

Aprovado para publicação a 02.07.2014

\section{Referências bibliográficas}

Assembleia da República (2000), Os 25 anos da "Questão de Timor-Leste" no Parlamento Português, 3 vols. Lisboa: Assembleia da República.

AusAid (2008), consultado a 12.06.2008, em http://www.ausaid.gov.au/country/country. cfm?CountryID=911\&Region=EastAsia.

Australian Government (2004), "Australia's Regional Engagement in South Pacific", Pacific Magazine, March 2004. Consultado a 29.05.2006, em http://www.dfat.gov.au. Butler, Michael J. (2012), "Ten Years After: (Re)Assessing Neo-Trusteeship and UN State-building in Timor-Leste", International Studies Perspectives, 13, 85-104.

Chopra, Jarat (2002), "Building State Failure in East Timor", Development and Change, 33(5), 979-1000.

Eriksen, Stein Sundstøl (2010), "The Theory of Failure and the Failure of Theory: 'State Failure'”, in Kristian Berg Harpviken (org.), Troubled Regions and Failing States: The Clustering and Contagion of Armed Conflicts (Comparative Social Research, 27). Bingley, UK: Emerald Group Publishing Limited, 27-50.

Fernandes, Moisés Silva (2005), "A União da República de Timor: o atrófico movimento nacionalista islâmico-malaio timorense, 1960-1975”, in Armando Marques Guedes; Nuno Canas Mendes (orgs.), Ensaios sobre nacionalismos em Timor-Leste. Lisboa: Instituto Diplomático - Ministério dos Negócios Estrangeiros, 355-431.

Fernandes, Moisés Silva (2006), "O Timor português na política externa de Suharto: o regresso ao status quo ante, 1965-1975”, Negócios Estrangeiros, 9.1, 272-338.

Hoadley, Stephen J. (1975), The Future of Portuguese Timor: Dilemmas and Opportunities. Singapore: ISEAS.

Ishizuka, Katsumi (2004), Australia's Policy Towards East Timor: Australia as Regional Hegemon?, UNU-CRIS Occasional Papers 0-2004/1, Department of International Business Management, University of Kyoei, Japão.

Jackson, Robert (1993), Quasi-States: Sovereignty, International Relations and the Third World. Cambridge: Cambridge University Press.

Jackson, Robert (2000), The Global Covenant: Human Conduct in a World of States. Oxford: Oxford University Press.

Mendes, Nuno Canas (2009), "The Dragon and the Crocodile: Chinese Interests in East Timor", Portuguese Journal of International Affairs, 1, 3-11. 
Mendes, Nuno Canas (2012), “Timor-Leste in 2011: The Prelude of a New Cycle?”, IPRIS Lusophone Countries Bulletin: 2011 Review, 46-50.

News.com.au (2006), consultado a 29.05.2006, em http://www.news.com.au/ story/01011719291485-2927700.html.

Oxfam (2004), consultado a 07.05.2008, em http://www.oxfam.org.au/media/article. php?id=66.

Rotberg, Robert I. (2002), "Failed States in a World of Terror", Foreign Affairs, 81(4), 127-140.

Rotberg, Robert I. (2004), "The Failure and Collapse of Nation-States: Breakdown, Prevention and Repair", in Robert I. Rotberg (org.), Why States Fail? Causes and Consequences. Princeton: Princeton University Press, 1-45.

Stilwell, Peter (1995), A condição bumana em Ruy Cinatti. Lisboa: Editorial Presença.

Wainwright, Elsina (2003), "Responding to State failure - The Case of Australia and Solomon Islands", Australian Journal of International Affairs, 57(3), 485-498. Consultado a 09.06.2008, em http://www.aspi.org.au/pdf/SI_AJIA.pdf.

Wiarda, Howard J. (2002), The Legacy of Portuguese Rule in Asia: Reasserting Influence in the Post-Colonial Era. Lisboa: CEPESA. 